\title{
Pain management for a case with Nutcracker syndrome, undergoing a newly developed bypass surgery
}

\author{
Lieven Ameye ${ }^{1}$, Joao Amaral ${ }^{2}$, Armando Lorenzo ${ }^{3,4}$ and Kazuyoshi Aoyama ${ }^{1,4^{*}}$ (D)
}

\section{To the Editor}

Nutcracker syndrome (NCS) is a rare condition characterized by a group of clinical manifestations, like hematuria and pain, and is most commonly due to compression of a left renal vein (LRV) between the superior mesenteric artery and the aorta. NCS is an important differential diagnosis of abdominal pain in young females because of its relatively high prevalence $[1,2]$. Chronic pain management is pivotal from the diagnosis of NCS to the end of treatment because the overall clinical course generally takes several years $[1,2]$. We herein present a case of NCS, who underwent a newly developed bypass surgery, describing the transition of its pain management.

A 17-year-old female presented with a 3-month history of difficulty urinating, daily painless gross hematuria, loin and back pain, nausea and vomiting, and weight loss. She described the pain as diffuse abdominal, present at all times, without any exacerbating or mitigating factors. Based on the history and clinical presentation, she required imaging to diagnose NCS.

Her Doppler ultrasonography and MRI showed the LRV stenosis consistent with NCS (Fig. 1A). A venogram under general anesthesia (GA) confirmed the diagnosis and demonstrated collateral drainage for possible bypass surgery. This study confirmed an area of compression of the LRV before entering the inferior vena cava: this was demonstrated as a lower contrast density area ("white area") in the LRV due to the compressed vein and smaller space for contrast to flow through (Fig. 1B). Perinephric collateral veins abnormally developed, likely due to partial obstruction and flow resistance. Because of her refractory pain despite chronic pain management over 7 months, including PO acetaminophen $1000 \mathrm{mg}$ and PO morphine $10 \mathrm{mg}$ both as needed, she elected to undergo a newly developed bypass surgery of her gonadal vein into the ipsilateral external iliac vein [3].

The team of urology, cardiovascular surgery, and radiology carried out her bypass surgery. She was $171 \mathrm{~cm}$ and $60 \mathrm{~kg}$ on the day of the surgery. GA was induced with propofol $150 \mathrm{mg}$ and fentanyl $100 \mu \mathrm{g}$, followed by tracheal intubation and was maintained with sevoflurane. Left-side transverse abdominis plane block was performed with $0.25 \%$ bupivacaine $20 \mathrm{ml}$ with adrenaline and dexmedetomidine $30 \mu \mathrm{g}$ for intraoperative pain management, in addition to intravenous morphine $2 \mathrm{mg}$. GA for the bypass was uneventful and required $7 \mathrm{~h}$ and $40 \mathrm{~min}$ in total. Her pain had improved (visual analog scale: 5 to 6) with less pain management, including PO acetaminophen $1000 \mathrm{mg}$ and PO morphine $5 \mathrm{mg}$ both as needed, on postoperative day 30 . PO morphine was discontinued 90 days after the surgery.

This case was the second successful case of newly developed bypass surgery. In the first case, the pain had entirely resolved after bypass surgery [3]. Hence, bypass

\footnotetext{
* Correspondence: kazu.aoyama@utoronto.ca

'Department of Anesthesia and Pain Medicine, The Hospital for Sick Children, Toronto, Canada

${ }^{4}$ Child Health Evaluative Sciences, Peter Gilgan Centre for Research and Learning, The Hospital for Sick Children Research Institute, Toronto, Canada Full list of author information is available at the end of the article
} 

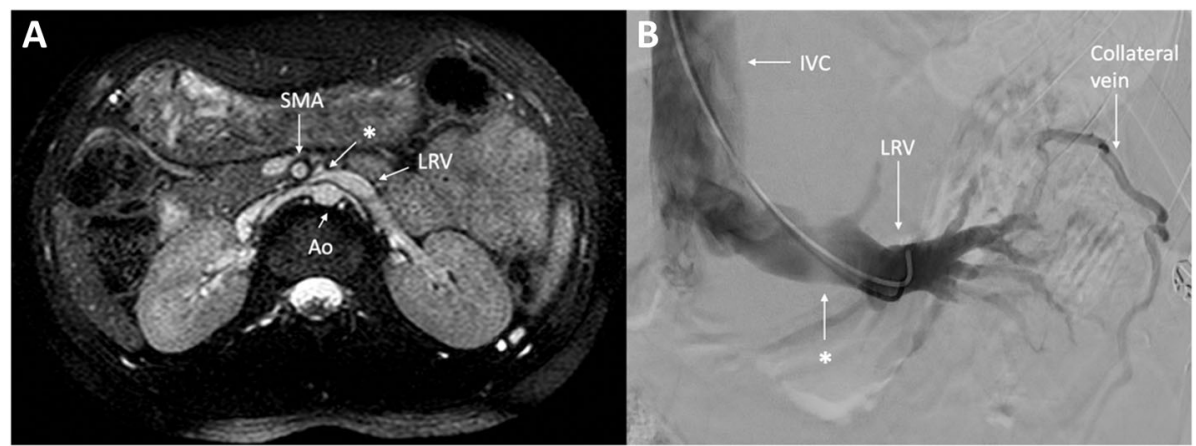

Fig. 1 A Magnetic resonance imaging of the kidneys and renal veins. Note the narrowing/pinching $\left(^{*}\right)$ between the SMA and the anterior aorta in the left renal vein (LRV) with a dilation proximal to the narrowing. B Venogram of the left renal vein. Note the remarkable low contrast density $\left(^{*}\right)$ before entry into the IVC, due to compression by the SMA and the anterior aorta. The perinephric vein of collateral drainage, due to partial obstruction and flow resistance, is abnormally observed. Ao, aorta; SMA, superior mesenteric artery; IVC, inferior vena cava; LRV, left renal vein

surgery can be a new surgical pathway for patients with refractory pain due to NCS, as bypass surgery is less invasive than a definitive surgical procedure such as an auto renal transplant.

\section{Acknowledgements}

As a recipient of Research Commendation, 2021-2023 Merit Awards Competition, Department of Anesthesiology \& Pain Medicine, University of Toronto, KA acknowledges the Department of Anesthesiology \& Pain Medicine, University of Toronto, and the Department of Anesthesia and Pain Medicine, Hospital for Sick Children, for their efforts to secure academic time to conduct the current work.

\section{Authors' contributions}

All authors took care of the case clinically. LA, AL, and KA obtained the consent from the patient. KA conceived the manuscript and helped LA draft the manuscript. JA determined most relevant and educational images from the image library. JA, AL, and KA provided input on the manuscript. All authors critically revised the manuscript and approved the final version of the manuscript.

\section{Funding}

Not applicable.

Availability of data and materials

All available data and materials are presented in the main document.

\section{Declarations}

Ethical approval and consent to participate

Obtained and uploaded along with the submission.

\section{Consent for publication}

Obtained and uploaded along with the submission.

\section{Competing interests}

The authors declare that they have no competing interests.

\section{Author details}

'Department of Anesthesia and Pain Medicine, The Hospital for Sick Children, Toronto, Canada. ${ }^{2}$ Department of Diagnostic Imaging - Division of Interventional Radiology, The Hospital for Sick Children, Toronto, Canada. ${ }^{3}$ Department of Urology, The Hospital for Sick Children, Toronto, Canada. ${ }^{4}$ Child Health Evaluative Sciences, Peter Gilgan Centre for Research and Learning, The Hospital for Sick Children Research Institute, Toronto, Canada.
Received: 11 May 2021 Revised: 11 May 2021

Accepted: 7 June 2021 Published online: 14 June 2021

\section{References}

1. He Y, Wu Z, Chen S, Tian L, Li D, Li M, et al. Nutcracker syndrome--how well do we know it? Urology. 2014;83(1):12-7. https://doi.org/10.1016/j.urology.2 013.08.033.

2. de Macedo GL, dos Santos MA, Sarris AB, Gomes RZ. Diagnóstico e tratamento da síndrome de quebra-nozes (nutcracker ): revisão dos últimos 10 anos. J Vasc Bras. 2018;17(3):220-8. https://doi.org/10.1590/1677-5449. 012417

3. Amaral J, Honjo O, Hannick JH, Rickard M, Lorenzo AJ. In situ gonadal vein valvulotomy and side-to-side gonado-iliac bypass for the management of Nutcracker syndrome in an adolescent with a solitary kidney and absence of pelvic congestion. Urology. 2019;126:200-3. https://doi.org/10.1016/j. urology.2018.12.033.

\section{Publisher's Note}

Springer Nature remains neutral with regard to jurisdictional claims in published maps and institutional affiliations.

\section{Submit your manuscript to a SpringerOpen ${ }^{\circ}$ journal and benefit from:}

- Convenient online submission

- Rigorous peer review

- Open access: articles freely available online

High visibility within the field

- Retaining the copyright to your article

Submit your next manuscript at $\boldsymbol{\nabla}$ springeropen.com 